\title{
Hydrostratigraphy and Its Relation to Ground-Water Potentiality of an Area of the Ganges River Delta in Bangladesh
}

\author{
M. Shahinuzzaman*, Sajib Mostafa, Khan M. Nasir Uddin, M. Khairul Islam, \\ Md. Alibuddin, M. Nozibul Haque \\ Department of Applied Physics, Electronics \& Communication Engineering, Islamic University, \\ Kushtia, Bangladesh \\ Email: "shahin.aece@gmail.com
}

Received 12 December 2015; accepted 7 January 2016; published 11 January 2016

Copyright (C) 2016 by authors and Scientific Research Publishing Inc.

This work is licensed under the Creative Commons Attribution International License (CC BY). http://creativecommons.org/licenses/by/4.0/

(c) (i) Open Access

\section{Abstract}

To identify the potential groundwater bearing zones for future groundwater resources development of the study area, an investigation has been made using lithology, groundwater monitoring and elevation data. The stratigraphic cross-sections of the area reveal six distinct hydrostratigraphic features viz. clay-silt-sand, fine sand, fine to medium sand, medium sand, medium to coarse sand and coarse sand. On the basis of lithological information, the groundwater bearing zone of the area has been divided into two main hydrostratigraphic units viz. aquitard and aquifer, which consist of clay-silt-sand and sands of different grain sizes respectively. The aquifer zone is further divided into two categories: "small scale aquifer" made dominantly of fine and "main aquifer" comprising of fine-medium to coarse sand. The annual fluctuation of water table in the study area is observed from $4.9 \mathrm{~m}$ to $5.6 \mathrm{~m}$. The area is demarcated as three different groundwater bearing zones based on Catastrophe theory using GIS.

\section{Keywords}

Hydrostratigraphy, Groundwater, Aquifer, Catastrophe Theory, Groundwater Potential Index

\section{Introduction}

Agriculture is the single largest producing sector of the economy in Bangladesh since it comprises about 30\% of the country's gross domestic product (GDP) and employs around 60\% of the total labor force [1]. Bangladesh is one of the most densely populated countries in the world. Agricultural production must be increased to meet the "Corresponding author. 
food needs of ever-increasing population of the country [2]. But, the water scarcity during the peak irrigation period is considered as a national problem in Bangladesh [3]-[6]. The problem stems from a low river flow in the dry season, making farmers more reliant on groundwater resources. Specifically, the reduction of fresh water flows in more recent years have made the people in the Ganges River dependent area, in the southwest part of Bangladesh, to progressively shift to an irrigation-based agriculture [7]-[11].

The study area in Kushtia district of Bangladesh situated in the lower Ganges basin mostly depends on groundwater for irrigation during dry season. More than $95 \%$ of the irrigation water in the area comes from groundwater [12].

The area is non-industrialized and therefore the livelihood of the people mostly depends on agricultural. The development of this area is closely related to intensive use of its land with ensured irrigation. It has been anticipated that future demand of water for irrigation in the region will be achieved through the development of groundwater resources. Groundwater movements in a geological system are controlled by lithology, stratigraphy and structure of the geologic formations [13] [14]. Therefore, assessment of subsurface geology and identification of geological layers suitable for bulk exploitation of groundwater are very important for the economy of the area.

In the present paper, a hydrostratigraphic study has been carried out for the identification of groundwater bearing zones in the study area using borehole lithology and groundwater fluctuation data. Two and three-dimensional geometry of sub-surface features has been developed to identify and assess the potential groundwater bearing zones.

\section{Site Information}

The study area (longitude $89^{\circ} 05^{\prime} 45^{\prime \prime} \mathrm{E}$ to $89^{\circ} 08^{\prime} 40^{\prime \prime} \mathrm{E}$ and latitude $23^{\circ} 54^{\prime} 30^{\prime \prime} \mathrm{N}$ to $23^{\circ} 56^{\prime} 25^{\prime \prime} \mathrm{N}$ ) is located in the northern side of Kushtia Sadar Upazila as shown in Figure 1.

The area is almost plain. The minimum elevation of $12 \mathrm{~m}$ is prevailing in the southwest and northeast corners whereas the maximum of $19 \mathrm{~m}$ exists in the middle to south and west of the area. The major river, the Ganges (Padma) and one of its distributaries, the Gorai are sustaining the environmental balance and socio-economic development of the area. The Ganges is flowing through the northeast side and the Gorai is flowing through the center of the study area from the north to the south.

The surficial geology of the study area is characterized by the floodplain and deltaic deposits that are generally young (Holocene age), gray colored, and composed of sand, silt and clay deposits [15]-[20]. The thickness of the upper silt and clay (USC) unit show that aquifers across the area are overlain by silt and clay sequences ranging from $<5$ to $30 \mathrm{~m}$ thick [21]. The composition of soil in different surface geological units varies as a function of proportions of sand, loam (silt), and clay [22]. The surface geology and soil composition which characterize shallow aquifers largely control the timing and pathways of groundwater recharge to aquifers [21] [23]. Groundwater in the area generally occurs at shallow ( $<10 \mathrm{mbgl}$ ) depth within widespread alluvial deposits [21]. Shallow groundwater levels essentially follow surface topography. The study area, like the rest part of Bangladesh, enjoys monsoon climate with seasonal wind reversal [24]. Based on rainfall, temperature and pressure, a yearlong cycle can be broken down into the four seasons: winter (December to February), summer or pre-monsoon (March to June), monsoon (July to September) and autumn or post monsoon (October to November). The study area receives an average annual rainfall of $1563 \mathrm{~mm}$ [25]. More than $72 \%$ of the total rainfall occurs during monsoon [26]. The rest $28 \%$ rainfall occurs due to western and northwestern depressions in winter and early summer. The study area experiences a mean temperature of $24^{\circ} \mathrm{C}$ with the lowest of $6^{\circ} \mathrm{C}$ in the winter and the highest of $43^{\circ} \mathrm{C}$. As the average relative humidity (74.33\%) is comparatively high, wet weather is observed in most part of the year. Therefore, the evapotranspiration is relatively low. The average population density, growth rate and sex ratio of the area studied are 986.45 per $\mathrm{km}^{2}, 1.5676 \%$ and 104 males per 100 females respectively [27].

\section{Materials and Methods}

Borehole lithology, groundwater monitoring and elevation data distributed over the study area are collected from Bangladesh Agricultural Development Corporation (BADC) for the hydrogeological study (Figure 1). The data have been processed, analyzed and interpreted with the aid of Rorkworks/2004 (version 6.6.26), SURFER (version 8.00), and ArcGIS (version 10.2.1.3497) for quantitative and spatial hydrogeological studies. The sub-surface geology has been studied up to the depth of $91 \mathrm{~m}$. 

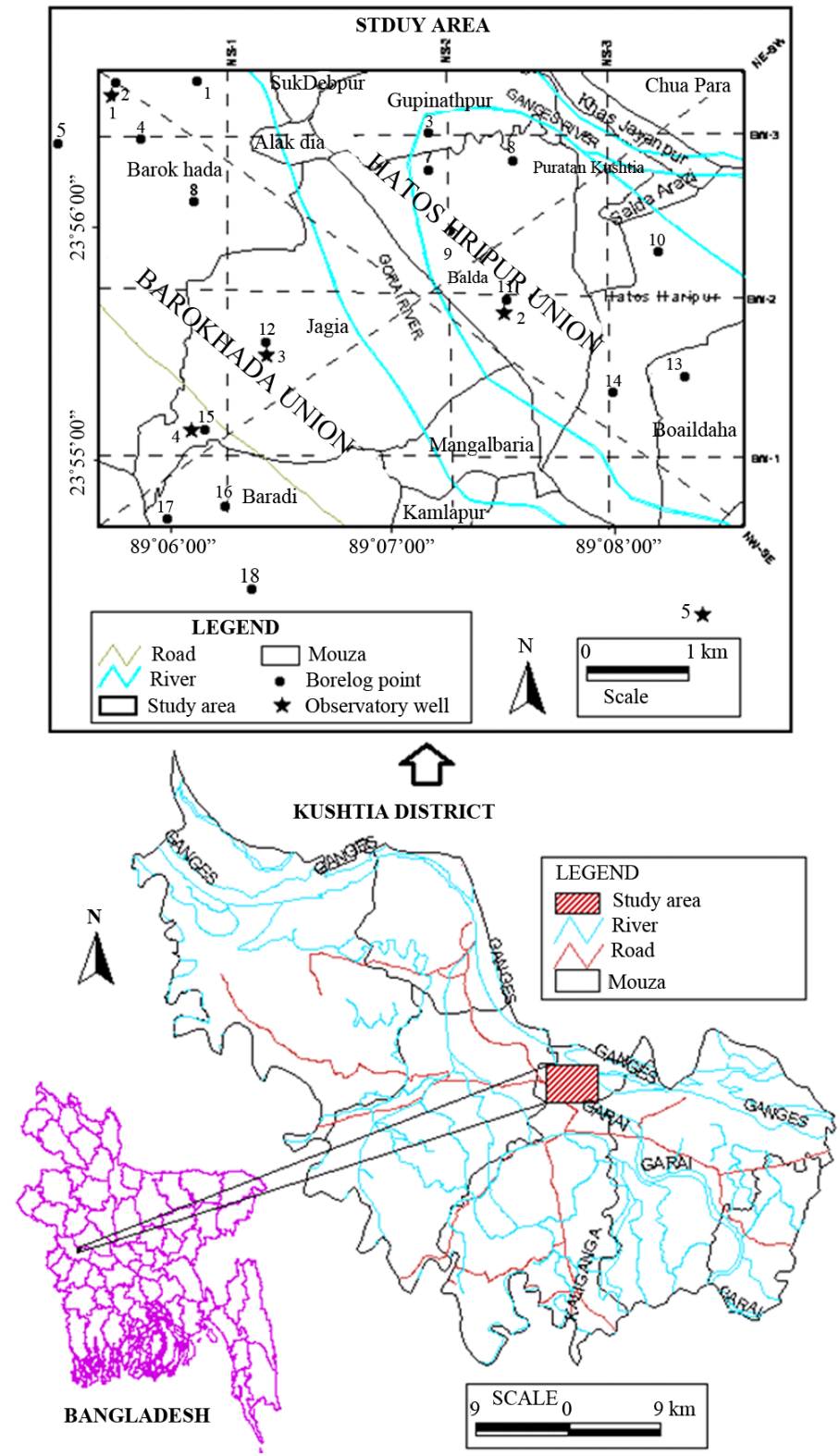

Figure 1. Location map of the study area along with borehole positions and profiles.

There are many factors which contribute to the occurrence and movement of groundwater, such as geology, geomorphology, soil, lineament density, surface water body, land cover, slope, rainfall as well as various physical properties of aquifer and vadose zone. However, the selection of number of indicators mainly depends on the availability of data [28], therefore the indicators varies from one study to another. In this study, three themes such as aquifer thickness $(A)$, aquifer media $(M)$ (ratio of medium-coarse sand to fine-fine medium sand) and aquitard thickness $(O)$ have been evaluated for the demarcation of groundwater bearing potential zones based on geological formation only.

The determined all the geological parameters are integrated by means of GIS using Catastrophe theory. Catastrophe theory is originated from the topology branch of mathematics. It was developed by French scientist Rene Thom in 1960s. The basic purpose of Catastrophe theory is to deal with the phenomena of discontinuity [29] [30]. The catastrophe method which is based on catastrophe theory draws on analytical hierarchy, utility function and fuzzy evaluation to obtain catastrophe fuzzy membership functions by normalized treatment of bifurcation set. The dependency of state variables on control variables is determined by catastrophic fuzzy mem- 
bership functions, rather than weight assigned by the users. In addition, different control variables have different impacts on the state of variables in multiple criteria evaluation method [31]. Initially the system is divided into sub-systems with different indicators according to the inner mechanism of the system being assessed. The initial data is normalized using catastrophe theory and fuzzy mathematics to give optimal or cleanest data. The multidimensional catastrophe fuzzy membership functions assigns values ranging from 0 to 1 to resolve incompatibility of various initial data [30]. There are seven catastrophe models viz. fold, cusp, dovetail, butterfly, swallowtail, hyperbolic umbilical and parabola umbilical. The models are shown in Table 1 where $x$ represent state variable and $a, b, c$ and $d$ represent control variables [32].

The catastrophe theory is applied using the following steps: i) selection of indicators, ii) standardization of data, iii) normalization and iv) computation for groundwater potential zone.

In order to assess the ground water potential zone accurately, the selection of appropriate sub-system and its indicators is necessary. In this study, the groundwater is considered as a system with aquifer thickness $(A)$, aquifer media $(M)$ and aquitard thickness $(O)$ as sub-systems. Here, the small scale aquifer and main aquifer is combined for the sub-system of aquifer thickness. Each sub-system has its own indicators to show how the area is potential for groundwater development. The elements in the system and sub-systems have a strong relation with each other. The detail of the sub-systems and their indicators with codes are shown in Table 2.

In multiple criteria decision making methods, different attributes or indices have different units of measurement. It is not possible to use the same units in analyzing the data in model.

Therefore, standardization of data is necessary. The standardization process makes the data dimensionless. Following equation are used to standardize the attributes in the present study.

For larger the better indices:

Table 1. Types of Catastrophe Model.

\begin{tabular}{cccc}
$\begin{array}{c}\text { Catastrophe } \\
\text { Model }\end{array}$ & $\begin{array}{c}\text { Control } \\
\text { Parameters }\end{array}$ & $\begin{array}{c}\text { State } \\
\text { Variables }\end{array}$ & Potential function \\
\hline Fold & 1 & 1 & $V_{a}(x)=\frac{1}{3} x^{3}+a x$ \\
Cusp & 2 & 1 & $V_{a b}(x)=\frac{1}{4} x^{4}+\frac{1}{2} a x^{2}+b x$ \\
Dovetail & 3 & 1 & $V_{a b c}(x)=\frac{1}{5} x^{5}+\frac{1}{3} a x^{3}+\frac{1}{2} b x^{2}+c x$ \\
Butterfly & 4 & 1 & $V_{a b c d}(x)=\frac{1}{6} x^{6}+\frac{1}{4} a x^{4}+\frac{1}{3} b x^{3}+\frac{1}{2} c x^{2}+d x$ \\
Oval umbilici point & 3 & 2 & $V_{a b c}(x, y)=x^{3}+y^{3}+a x y+b x+c y$ \\
Elliptic umbilici point & 3 & 2 & $V_{a b c}(x, y)=x^{3}-x y^{2}+a\left(x^{2}+y^{2}\right)+b x+c y$ \\
Parabolic umbilici point & 4 & 2 & $V_{a b c}(x, y)=x^{2} y+x^{4}+a x^{2}+b y^{2}+c x+d y$ \\
\hline
\end{tabular}

Table 2. Indicators for Groundwater potential zone.

\begin{tabular}{ccc}
\hline Sub-System & Indicator & Code \\
\hline & Excellent & C1 \\
Aquifer thickness $(A)$ & Very High & C2 \\
& High & C4 \\
& Moderately High & C5 \\
Aquifer media $(M)$ & Excellent & C7 \\
& Very High & C8 \\
& High & C9 \\
Aquitard thickness $(O)$ & Medium & C10 \\
& Excellent & C11
\end{tabular}




$$
x_{i}^{\prime}=\frac{x_{i}-x_{i(\min )}}{x_{i(\max )}-x_{i(\min )}}
$$

For smaller the better:

$$
x_{i}^{\prime}=\frac{x_{i(\max )}-x_{i}}{x_{i(\max )}-x_{i(\min )}}
$$

where, $i$ is the index or attribute, $x_{\mathrm{i}}$ is the original value of $i, x_{i(\max )}$ and $x_{i(\min )}$ are maximum and minimum values.

Generally, normalization of raw data is done after dividing the system into subsystems. Normalization formula is the basics for calculating the catastrophe theory. In this study, the formulas used for normalizing catastrophe model are given in Table 3 .

In order to assess the groundwater bearing potential zones, initially the maps of aquifer thickness $(A)$, aquifer media $(M)$ and aquitard thickness $(O)$ have been generated using ArcGIS. Catastrophe theory is used in assigning the weights of sub-system indicators. The maps are then integrated using overlay tool in ArcGIS. The groundwater potential index (GWPI) of the integrated layer is calculated using the following equation [34]-[36]:

$$
\mathrm{GWPI}=\left(A_{w} A_{r}+M_{w} M_{r}+O_{w} O_{r}\right)
$$

where $A, M$ and $O$ represent aquifer thickness, aquifer media and aquitard thickness respectively. The subscripts, $w$ and $r$ represent weight and rank respectively. Here, the ranks of the sub-systems have been assigned depending on their relative importance, i.e. the larger the average normalized value the greater rank of the sub-system.

\section{Results and Discussion}

\subsection{Stratigraphy}

The three dimensional stratigraphic model of the study area prepared with the aid of Rorkworks software is shown in Figure 2(a). The model shows that the area mainly consists of two sub-surface layers, namely a top clay-silt-sand layer and a sandy layer of different grain sizes.

The sandy formation can be clearly sub-divided into fine, fine-medium, medium, medium-coarse and coarse sand. To observe the cross-sectional views in various parts of the investigated area, different representative vertical cross-sections along the profiles have been prepared and presented in Figure 2(b)-(d) respectively. These figures have been drawn considering the heights of different interfaces with respect to mean sea level (msl). The cross-sections furnish a clear picture of different stratigraphic units or layers underneath. Among the layers the top clay-silt-sand layer, fine sand, fine-medium and coarse sandy layers are present everywhere.

\subsection{Hydrostatigraphic Units}

Considering the clay-silt-sand and fine sand as individual units and the rest sandy formations as aquiferic materials, a three dimensional stratigraphic model has been reconstructed as shown in Figure 3(a). Sub-regional stratigraphic sections along the corners and middle of the edges are shown in Figure 3(b).

It is clear from the figure that the subsurface formations can be divided into three main layers. The first layer consists of top clay-silt-sand, the second layer is dominantly made of fine sand and the third layer consists of fine-medium, medium, medium-coarse and coarse sand.

On the basis of borehole information the groundwater bearing sequence of the area can be divided into two main hydrostratigraphic units viz. (a) aquitard and (b) aquifer.

\begin{tabular}{cccc}
\multicolumn{4}{l}{ Table 3. Normalization Formulas for Catastrophe theory [33]. } \\
\hline $\begin{array}{c}\text { Control } \\
\text { Variable }\end{array}$ & $\begin{array}{c}\text { State } \\
\text { Variable }\end{array}$ & Name & Normalization formula \\
\hline 4 & 1 & Butterfly & $x_{a}=a^{1 / 2}, x_{b}=b^{1 / 3}, x_{c}=c^{1 / 4}$ and $x_{d}=d^{1 / 5}$ \\
5 & 1 & Wigwam & $x_{a}=a^{1 / 2}, x_{b}=b^{1 / 3}, x_{c}=c^{1 / 4}, x_{d}=d^{1 / 5}$ and $x_{e}=e^{1 / 6}$ \\
\hline
\end{tabular}




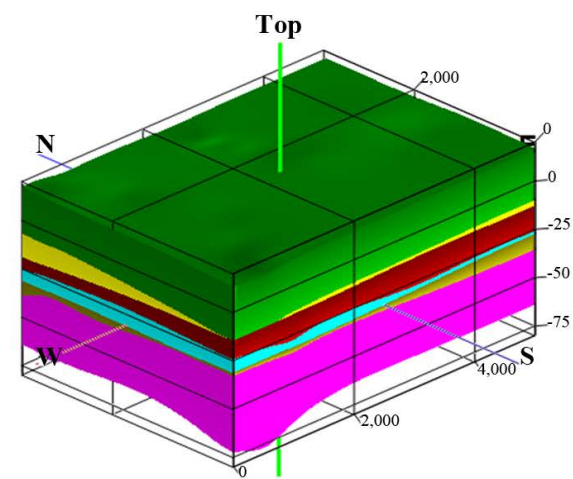

(a) Base

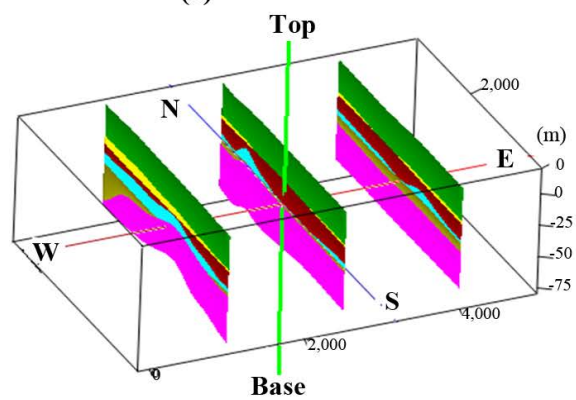

(c)

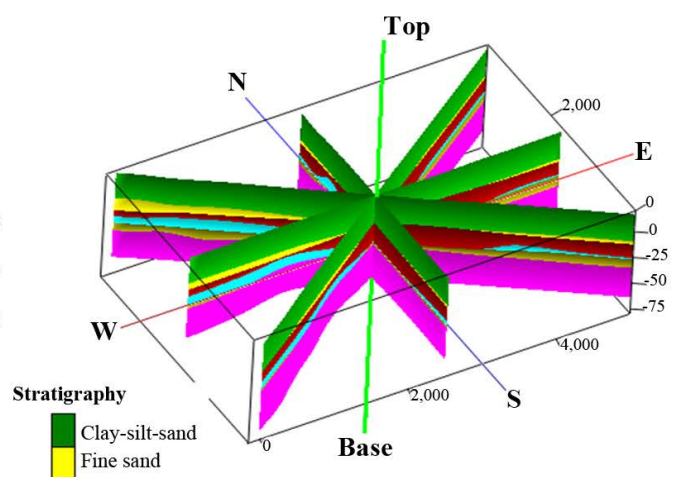

(b)

Fine-medium sand

Medium sand

Medium-coarse sand

Coarse sand

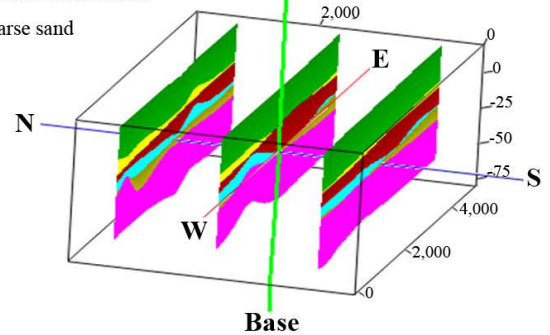

(d)

Figure 2. (a) Three-dimensional stratigraphic model, (b) fence diagram along the corners and middle of the edges, (c) fence diagram along north-south, and (d) fence diagram along east-west direction.

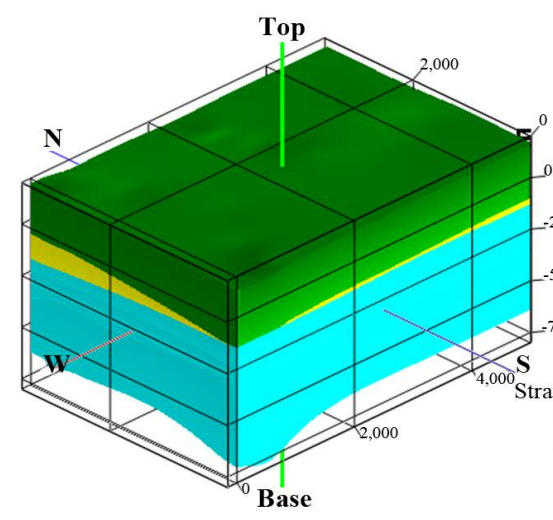

(a)

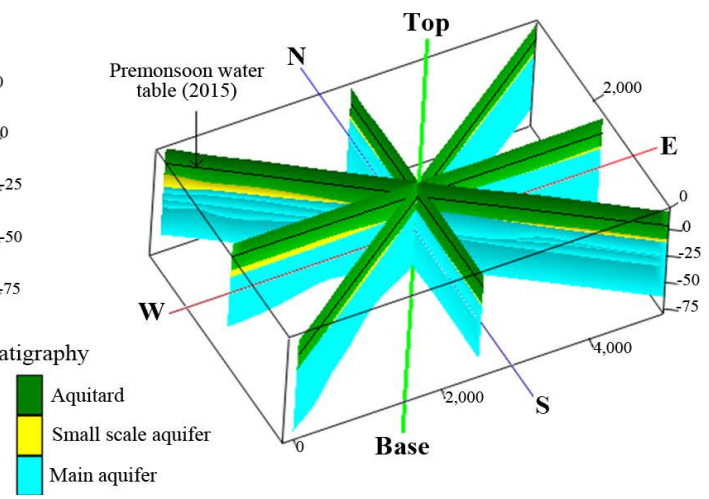

(b)

Figure 3. (a) Reconstructed three-dimensional stratigraphic model and (b) fence diagram along the corners and middle of the edges.

\subsubsection{Aquitard}

The moderately thick top layer made up of primarily clay and silt with sand of Quaternary age is characterized by high porosity. The shaded contour map of the thickness of this aquitard layer is shown in Figure 4(a). Most of the places, the thickness of this layer lies above $20 \mathrm{~m}$, however there exists a pocket of $10-20 \mathrm{~m}$ thick in the middle of the area. This layer may be used as the groundwater source only for the dug wells as the permeability and productivity are very low.

\subsubsection{Aquifer}

The lithological data of the study area have confirmed the presence of aquiferic materials of different granular, which may be divided into two categories. 


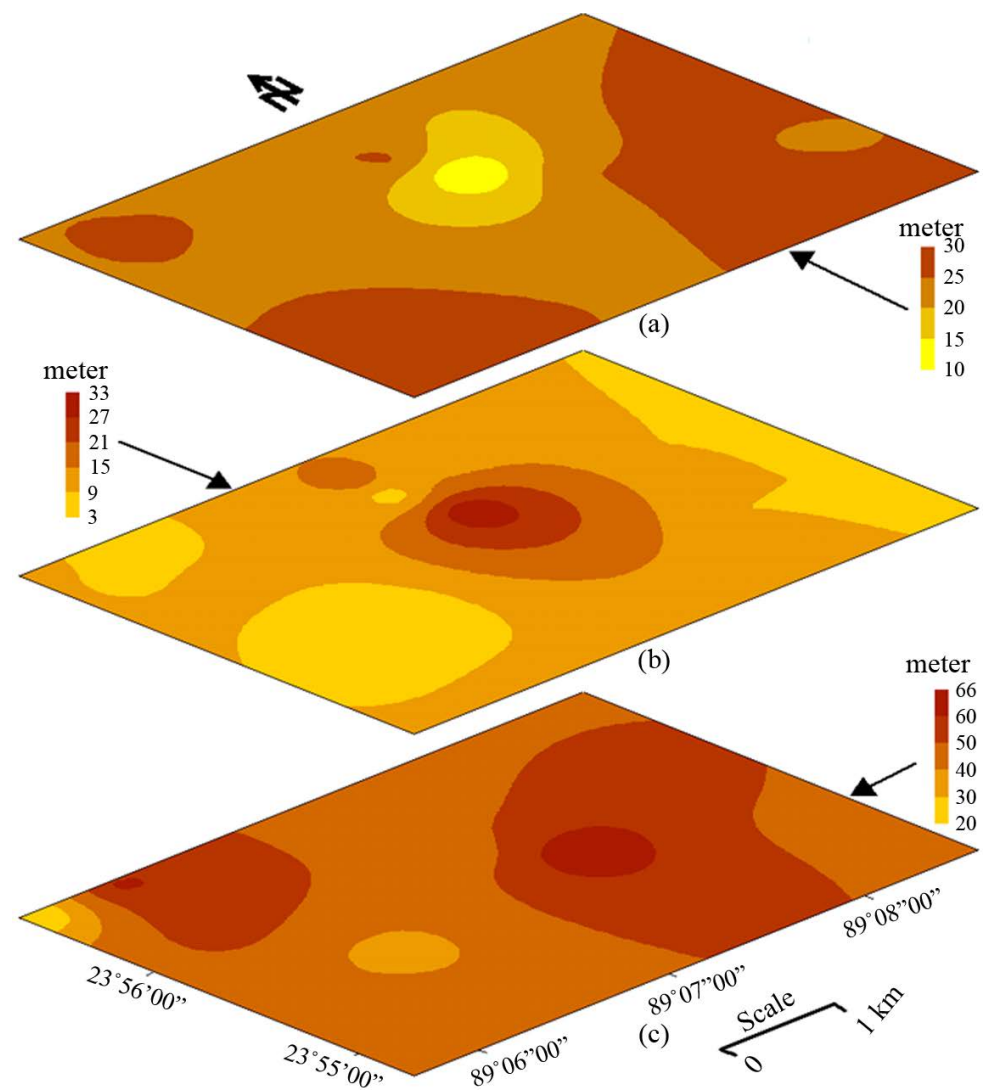

Figure 4. Lateral variation of the thickness of: (a) aquitard, (b) shallow small scale aquifer and (c) main aquifer.

i) Upper shallow small scale aquifer: The borehole information indicates the presence of a layer consists of fine sand just below the aquitard almost everywhere in the study area. The shaded contour map of the thickness of this aquifer is shown in Figure 4(b). The thickness of this layer varies from $3 \mathrm{~m}$ to $33 \mathrm{~m}$. However, in most of the area it is greater than $9 \mathrm{~m}$. This layer may be used as the small-scale groundwater abstracting source for the hand- and shallow tube-wells because of their medium permeability and productivity.

ii) Main Aquifer: The deeper layer comprising of fine-medium, medium, medium-coarse and coarse sand is known as the main aquifer. This aquifer is characterized by moderate porosity and high permeability and therefore, capable of providing large quantity of groundwater. The position of the screen of deep tube wells are sunk within this zone. Considering the development potential of groundwater, these formations can be considered as most productive source. Therefore, the assessment of the depth and thickness of this composition is of great importance in groundwater exploration in the area. The thickness of the main aquifer of the study area is shown in Figure 4(c). The thickness of this layer varies from 20 to $66 \mathrm{~m}$ within the depth of 25 - $43 \mathrm{~m}$. However, in most of the area, the thickness is greater than $40 \mathrm{~m}$. The presence of thick main aquifer reveals that the study area is favorable for large-scale groundwater exploration.

\subsection{Hydrostratigraphic Correlation}

The vertical and lateral boundaries of hydrostratigraphic and lithostratigraphic units can be designated on the basis of significant breaks in their characteristics as are identifiable and traceable in the field [14] [37]. Considering the chronology of different established formations, a generalized hydrostratigraphic succession is proposed and presented in the Table 4.

\subsection{Groundwater Level Fluctuation}

The upper surface of the zone of saturation is called the water table or phreatic surface which separates the zone 
Table 4. Hydrostratigraphic correlation.

\begin{tabular}{cccc}
\hline Lithologic Description & Depth $(\mathrm{m})$ & Thickness $(\mathrm{m})$ & Aquifer Types \\
\hline $\begin{array}{c}\text { Clay-silt-sand } \\
\text { Fine sand. }\end{array}$ & 0 & $10-30$ & Aquitard \\
$\begin{array}{c}\text { Fine-medium, medium, medium-coarse } \\
\text { and coarse sand. }\end{array}$ & $10-30$ & $3-33$ & Small-Scale Aquifer \\
\hline
\end{tabular}

of saturation from the overlying zone of aeration. It is a graphic representation of the hydraulic slope of the free water body and is usually a "subdued replica" of the surface topography. The depth of the water table or isobaths of the water table depict the inequalities in the position of water table with respect to the ground surface and are useful in delineating recharge and discharge areas, locating sites for wells and dealing with drainage, artificial recharge or other problems in which the depth of the water table is critical. Groundwater observation level data is an important input parameter to the groundwater resource assessment. The groundwater levels in the study area naturally fluctuate in response to a sequence of climatic events and to constraints imposed by the hydrogeologic and topographic characteristics [38]. The water table starts moving upward and reaches to minimum depth from the land surface in August/September. To evaluate the groundwater fluctuation condition of the study area, the water table data are used to prepare the maps of the spatial variations of pre-monsoon, postmonsoon water table as well as groundwater fluctuation of the year 2014 (Figure 5). The ranges of pre-monsoon and post-monsoon water level are varying from $7.6 \mathrm{~m}$ to $8.1 \mathrm{~m}$ and $2.4 \mathrm{~m}$ to $3.0 \mathrm{~m}$ respectively. The annual fluctuation of water table from pre-monsoon to post-monsoon of 2014 has been estimated and displayed in Figure 5(c). The maximum fluctuation of $5.6 \mathrm{~m}$ occurs in the west of study area whereas the northeast side has the minimum fluctuation of $4.9 \mathrm{~m}$. The records of the position of water table of different observation wells confirm that the fluctuation of water table generally occurs within the aquitard.

\subsection{Demarcation of Groundwater Bearing Potential Zone}

In this study, the indicators of groundwater sub-systems namely aquifer thickness $(A)$, and aquitard thickness $(O)$ meet the butterfly Catastrophe model whereas indicators of aquifer media $(M)$ meet Wigwam model. The index values for all three sub-systems are the average values for different classes observed in the study area. The index values are standardized according to Equation 1 and Equation 2.

After standardization of raw data the normalized values are obtained from normalization formulas given in Table 3. For example, the values of the indicators of aquifer thickness are calculated using butterfly model as, $\mathrm{X}_{\mathrm{C} 1}=\left((1)^{\wedge} 0.5\right)=1, \mathrm{X}_{\mathrm{C} 2}=\left((0.634)^{\wedge} 0.333\right)=0.859, \mathrm{X}_{\mathrm{C} 3}=\left((0.317)^{\wedge} 0.25\right)=0.750$, and $\left.\mathrm{X}_{\mathrm{C} 4}=(0)^{\wedge} 0.2\right)=0 . \mathrm{The}$ average of the indicators, $A=\left(\mathrm{X}_{\mathrm{C} 1}+\mathrm{X}_{\mathrm{C} 2}+\mathrm{X}_{\mathrm{C} 3}+\mathrm{X}_{\mathrm{C} 4}\right) / 4=0.652$. Similarly applying the same procedure we get $M=0.699$ and $O=0.658$. In all cases two digits after decimal point were taken though $3^{\text {rd }}$ or $4^{\text {th }}$ digits after decimal point are significant. So the values are the approximate after this consideration. The values are then ranked from 1 to 3. The highest is aquifer media and therefore, ranked as 3. The aquitard thickness is ranked as 2 and aquifer thickness is ranked as 1 . Calculated weights and ranks of the sub-systems are shown in Table 5. The values of weights and ranks of aquifer media, aquitard thickness and aquifer thickness are inserted in Equation 3 to calculate the groundwater potential index (GWPI) using overlay tool of ArcGIS. Finally, the groundwater potential indices are classified to demarcate different groundwater bearing potential zones in the study area (Figure 6). Qualitatively the zone having GWPI of 4 - 5.3 distributed from the middle to the south, northeast and northwest corner of the area is a very good prospective groundwater potential with the probability of high yield. Few pockets with GWPI of 2 - 4 are also quite promising for good groundwater potential. A moderately good groundwater potential zones having GWPI of $0-2$ is prevailing in the southwest and northwest corners, and middle of the northern side of the area.

\section{Conclusions}

The stratigraphic cross-sections of the area reveal six distinct hydrostratigraphic features in accordance of their vertical distribution and lithological composition. Two groundwater bearing sequences: i) small scale aquifer consisting of fine sand and ii) the main aquifer comprising of fine-medium to coarse sand have been identified within the depth of 25 - $43 \mathrm{~m}$ in the study area. The position of water table at different observation wells confirms 


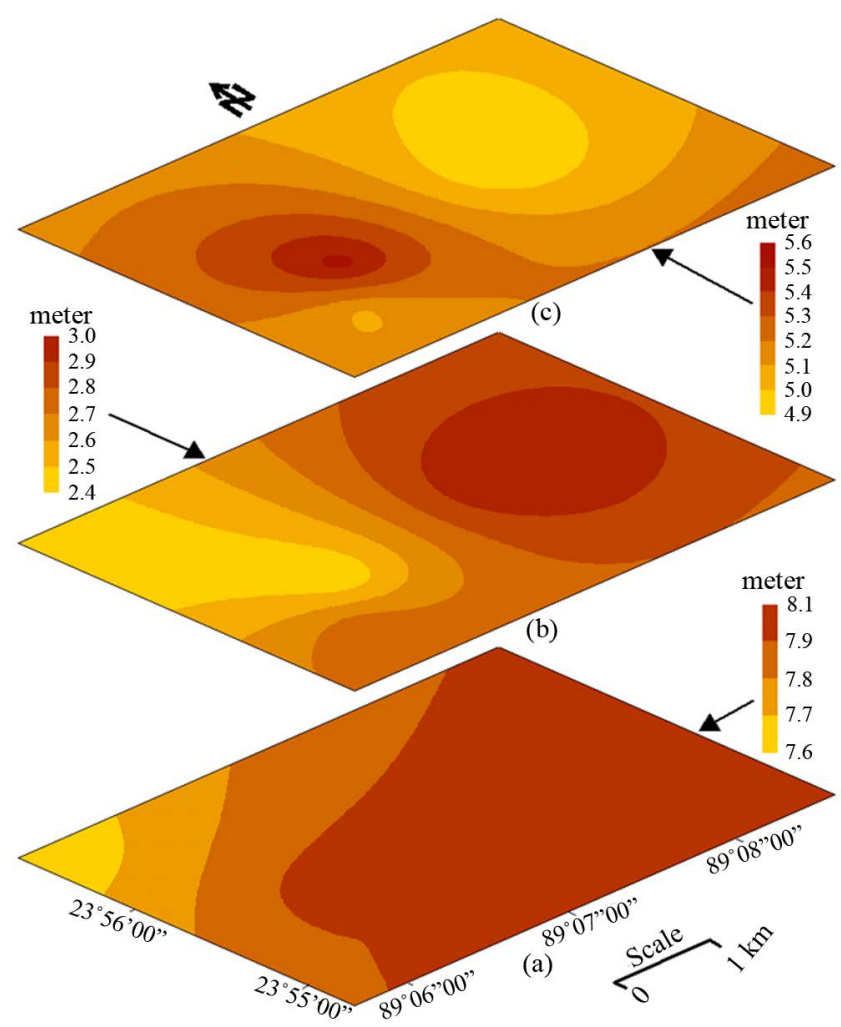

Figure 5. Spatial variation of: (a) pre-monsoon water table, (b) post-monsoon water table and (c) groundwater level fluctuation of 2014 in the study area.

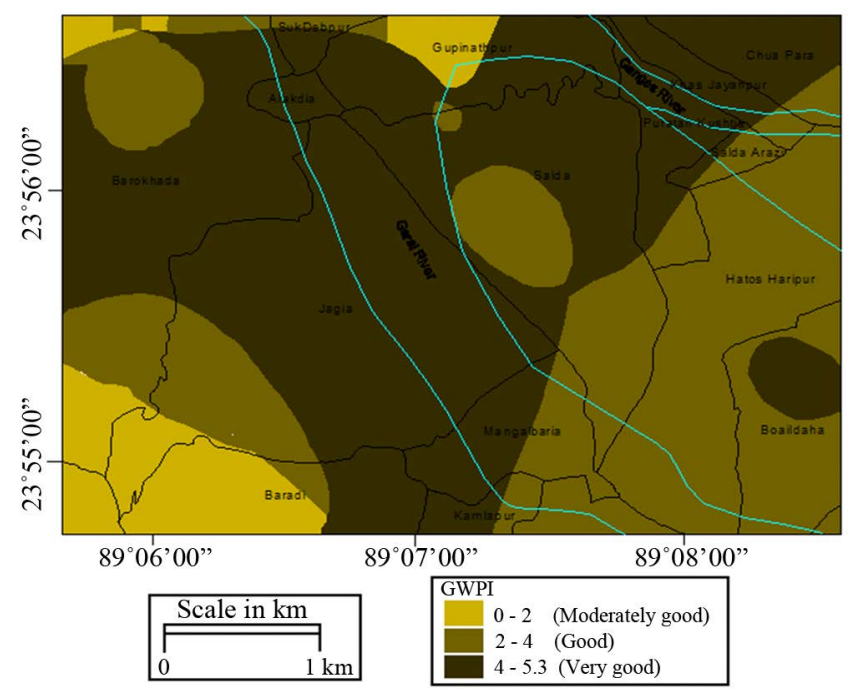

Figure 6. Groundwater potential index map of the study area.

that the water table fluctuates within the aquitard with a varying range of 4.9 - $5.6 \mathrm{~m}$. The study area has been categorized into three different groundwater bearing potential zones using Catastrophe theory. On the basis of the hydrostratigraphy the area may be assumed favorable for groundwater development. Since the usable aquifer is unconfined in nature, the large-scale development should be avoided otherwise ecological imbalance would affect the environmental system. Therefore, government policy of poverty alleviation through introduction of groundwater based irrigation can be implemented in the study area. It can also be expected that the findings of 
Table 5. Calculated weights and ranks of the sub-systems.

\begin{tabular}{|c|c|c|c|c|c|c|}
\hline Sub-system & Indicators & $\begin{array}{l}\text { Index } \\
\text { value }\end{array}$ & $\begin{array}{l}\text { Standardized } \\
\text { value }\end{array}$ & $\begin{array}{c}\text { Normalized } \\
\text { value }\end{array}$ & $\begin{array}{l}\text { Normalized value } \\
\text { (Average) }\end{array}$ & Rank \\
\hline \multirow{4}{*}{ Aquifer thickness in meter $(A)$} & Excellent & 68.5 & 1.00 & 1.00 & \multirow{4}{*}{0.65} & \multirow{4}{*}{1} \\
\hline & Very High & 57.0 & 0.63 & 0.86 & & \\
\hline & High & 47.0 & 0.32 & 0.75 & & \\
\hline & Moderately High & 37.0 & 0.00 & 0.00 & & \\
\hline \multirow{5}{*}{$\begin{array}{l}\text { Aquifer media }(M) \text { (ratio of } \\
\text { medium-coarse sand to fine-fine } \\
\text { medium sand) }\end{array}$} & Excellent & 9.6 & 1.00 & 1.00 & \multirow{5}{*}{0.70} & \multirow{5}{*}{3} \\
\hline & Very High & 7.5 & 0.74 & 0.90 & & \\
\hline & High & 5.5 & 0.49 & 0.84 & & \\
\hline & Moderately High & 3.5 & 0.25 & 0.76 & & \\
\hline & Medium & 1.5 & 0.00 & 0.00 & & \\
\hline \multirow{4}{*}{ Aquitard thickness in meter $(O)$} & Excellent & 12.5 & 1.00 & 1.00 & \multirow{4}{*}{0.66} & \multirow{4}{*}{2} \\
\hline & Very High & 17.5 & 0.67 & 0.87 & & \\
\hline & High & 22.5 & 0.33 & 0.76 & & \\
\hline & Medium & 27.5 & 0.00 & 0.00 & & \\
\hline
\end{tabular}

the present study will help national and local policy makers and water practitioners in planning and management of water resources.

\section{References}

[1] Shahid, S., Chen, X.Y. and Hazarika, M.K. (2006) Evaluation of Groundwater Quality for Irrigation in Bangladesh Using Geographic Information System. Journal of Hydrology and Hydromechanics, 54, 3-14.

[2] Shahid, S. (2011) Impact of Climate Change on Irrigation Water Demand of Dry Season Boro Rice in Northwest Bangladesh. Climatic Change, 105, 433-453. http://dx.doi.org/10.1007/s10584-010-9895-5

[3] World Bank (2002) Bangladesh 2020: A Long Run Perspective Study (Asiatic Society, Bangladesh). The University Press, Dhaka.

[4] BADC (2005) The Minor Irrigation Survey Report of 2005. Bangladesh Agricultural Development Corporation, Dhaka.

[5] Shahid, S. (2010) Spatial Assessment of Groundwater Demand in Northwestern Bangladesh. International Journal of Water, 5, 267-283. http://dx.doi.org/10.1504/IJW.2010.030590

[6] Sattar, G.S., Keramat, M. and Shahid, S. (2014) Deciphering Transmissivity and Hydraulic Conductivity of the Aquifer by Vertical Electrical Sounding (VES) Experiments in Northwest Bangladesh. Applied Water Science, 1-11. http://dx.doi.org/10.1007/s13201-014-0203-9

[7] BBS (2001) Population Census of Bangladesh. Bangladesh Bureau of Statistics, Statistic Division, Ministry of Planning, Government of the People's Republic of Bangladesh, Dhaka.

[8] GoB (2002) Second National report on Implementation of United Nations Convention to Combat Desertification, Bangladesh. Government of Bangladesh (GoB) Report, Ministry of Environment and Forests, Dhaka.

[9] Momin, M.A. (2003) Impact of Farakka Barrage over the South-Western Region of Bangladesh. The International Conference, Dhaka, 12 December 2003, 1-15 (Mimeographed).

[10] Shahid, S. and Hazarika, M.K. (2010) Groundwater Droughts in the Northwestern Districts of Bangladesh. Water Resources Management, 24, 1989-2006. http://dx.doi.org/10.1007/s11269-009-9534-y

[11] BBS (2012) Census of Agriculture (2008) Bangladesh. Bureau of Statistics, Government of the People’s Republic of Bangladesh, Dhaka.

[12] Shahid, S., Rahman, M.M. and Keramat, M.M. (2012) Climate Change and Its Impacts on Irrigation and Groundwater Resources: A Case Study of Northwest Bangladesh. Lambert Academic Publishers, Germany, 118.

[13] Karanth, K.R. (1989) Hydrogeology. Tata McGrow-Hill Publishing Co. Ltd., Powai, 458.

[14] Nath, S.K., Patra, H.P. and Shahid, S. (2000) Geophysical Prospecting for Groundwater. A.A. Balkema, Rotterdam, 254.

[15] Haque, M.N., Keramat, M., Alamgir, M. and Shahid, S. (2011) Hydrostratigraphic Study in the Western Part of Bangladesh in Relation to Groundwater Potentiality. Journal of Earth Science and Engineering, 7, 1668-1674.

[16] Haque, M.N. and Hasan, M.A.F.M.R. (2001) Groundwater Potentiality in the Western Part of Kushtia District, Bangladesh. Journal of Applied Science and Technology, 2, 93-99. 
[17] Haque, M.N. and Hasan, M.A.F.M.R. (2002) Sub-Surface Formations and Groundwater Flow in Daulatpur and Bheramara Thana of Kushtia District, Bangladesh. Journal of the Bangladesh National Geographical Association, 30, 4154.

[18] Ali, S. (2006) Interpretation of Hydrogeological and Geoelectrical Data for the Evaluation of Groundwater Potentiality in the Southern Part of Daulatpur Upazila, Kushtia. Unpublished Master's Thesis, Department of Applied Physics, Electronics \& Communication Engineering, Islamic University, Kushtia, 83.

[19] UNDP (1982) The Hydrogeological Condition of Bangladesh. Groundwater Survey Technical Report DP/UN/BGD74-0071, United Nation Development Programme, New York.

[20] BGS (British Geological Survey) and DPHE (Department of Public Health and Engineering) (2001) Arsenic Contamination of Groundwater in Bangladesh. In: Kinniburgh, D.G. and Smedley, P.L., Eds., British Geologic Survey Report WC/00/19, BGS, Keyworth, 257.

[21] MPO (Master Plan Organization) (1987) Groundwater Resources of Bangladesh. Technical Report No. 5, Master Plan Organization, Dhaka. Hazra, USA; Sir M MacDonald, UK; Meta, USA; EPC, Bangladesh.

[22] BARC (1988) Agro Ecological Zones (AEZ) Inventory Map, Scale: 1:250,000. Bangladesh Agricultural Research Council, Dhaka.

[23] WARPO (Water Resources Planning Organization) (2000) National Water Management Plan Project Draft Development Strategy. Main Final, Volume 2, WARPO, Dhaka.

[24] Shahid, S. (2010) Recent Trends in the Climate of Bangladesh. Climate Research, 42, 185-193. http://dx.doi.org/10.3354/cr00889

[25] Shahid, S. and Khairulmaini, O.S. (2009) Spatio-Temporal Variability of Rainfall over Bangladesh during the Time Period 1969-2003. Asia-Pacific Journal of Atmospheric Sciences, 45, 375-389.

[26] BWDB (2000) Environmental Baseline of Gorai River Restoration Project. EGIS II, Dhaka, 190.

[27] Aktar, N., Sarker, M.L.R. and Hassan, M.Z. (2000) Regional Imbalance of Agricultural Development in Bangladesh: 1974-76 to 1989-91. Journal of the Bangladesh National Geographical Association, 21-26, 45-56.

[28] Ahmed, K., Shahid, S., Harun, S.B., Ismail, T., Nawaz, N. and Shamsudin, S. (2014) Assessment of Groundwater Potential Zones in an Arid Region Based on Catastrophe Theory. Earth Science Informatics, 8, 539-549. http://dx.doi.org/10.1007/s12145-014-0173-3

[29] Kozak, J.J. and Benham, C.J. (1974) Denaturation: An Example of a Catastrophe. Proceedings of the National Academy of Sciences of the United States of America, 71, 1977-1981. http://dx.doi.org/10.1073/pnas.71.5.1977

[30] Wang, W., Liu, S., Zhang, S. and Chen, J. (2011) Assessment of a Model of Pollution Disaster in Near-Shore Coastal Waters Based on Catastrophe Theory. Ecological Modelling, 222, 307-312. http://dx.doi.org/10.1016/j.ecolmodel.2010.09.007

[31] Feng, P., Li, S.-F. and Li, J.-Z. (2008) Catastrophe Theory-Based Risk Evaluation of Groundwater Environment. Journal of Natural Disasters, 2, 1-4.

[32] Wang, X.-J., Zhang, J.-Y., Shahid, S., Xia, X.-H., He, R.-M. and Shang, M.-T. (2014) Catastrophe Theory to Assess Water Security and Adaptation Strategy in the Context of Environmental Change. Mitigation and Adaptation Strategies for Global Change, 19, 463-477.

[33] Cheng, C.-H., Liu, Y.-H., and Lin, Y. (1996) Evaluating a Weapon System Using Catastrophe Series Based on Fuzzy Scales. Proceedings of the 1996 Asian Fuzzy Systems Symposium on Soft Computing in Intelligent Systems and Information Processing, Kenting, 11-14 December 1996, 212-217.

[34] Shahid, S., Nath, S.K. and Roy, J. (2000) Groundwater Potential Modelling in a Soft Rock Area Using a GIS. International Journal of Remote Sensing, 21, 1919-1924. http://dx.doi.org/10.1080/014311600209823

[35] Hutti, B. and Nijagunappa, R. (2011) Identification of Groundwater Potential Zone Using Geoinformatics in Ghataprabha Basin, North Karnataka, India. International Journal of Geomatics and Geosciences, 2, 91-109.

[36] Al-Abadi, A. and Al-Shamma'a, A. (2014) Groundwater Potential Mapping of the Major Aquifer in Northeastern Missan Governorate, South of Iraq by Using Analytical Hierarchy Process and GIS. Journal of Environment and Earth Science, 4, 125-149.

[37] Harland, W.B., Armstrong, R.L., Cox, A.V., Craig, L.E., Smith, A.G. and Smith, D.G. (1990) A Geologic Time Scale. Cambridge University Press, Cambridge, 263.

[38] Adhikary, S.K., Chaki, T., Rahman, M.M. and Gupta, A.D. (2013) Estimating Groundwater Recharge into a Shallow Unconfined Aquifer in Bangladesh. Journal of Engineering Science, 4, 11-22. 